\title{
Aplikasi Pengelolaan Dokumen dan Arsip berbasis Web untuk mengatur Sistem kearsipan dengan menggunakan Metode Waterfall
}

\author{
Ridwanto, Dwi Ade Handayani Capah \\ Program Studi Sistem Informasi \\ Universitas Mercu Buana \\ Jakarta, Indonesia \\ 41816310062@student.mercubuana.ac.id,dwi.ade@mercubuana.ac.id
}

\begin{abstract}
Archives or documents have an important role in the effectiveness of activities in companies and organizations as a source of information and references. Not a few companies that have hundreds of archives stored in the company up to a lot of cabinets or shelves used to store records and documents, but the system used in archival storage is still relatively ineffective because there are still many companies that use manual systems in storing and borrowing records. This causes the archive is often found messy and not stored in place even difficult to find when needed so that the work becomes less effective. Not a few employees take arbitrary records and documents. Problems like this are found in the filing system of large companies or organizations. In large companies it is definitely saving a lot of important records that will be needed or borrowed from time to time. The problem is because many of their archives and irregular archive storage will take time making it less efficient in PT and archive lending without any memorandum or proof of lending at risk of missing archives or broken. From the problems above, an application was made to manage documents and archives. The application uses the waterfall method so that the system can run more orderly and neatly. With this application it is expected that the filing system can run more regularly. And it is also expected to develop this application.

Keyword : Archives, Time, Web
\end{abstract}

\begin{abstract}
Abstrak-Beberapa faktor menyebabkan rendahnya kualitas dan produktivitas kopi di Indonesia. Alasan utama permasalahan ini adalah gangguan hama dan penyakit. Sebagian besar petani kopi di Indonesia, khususnya di Provinsi Lampung adalah petani kopi yang tidak terdidik. Para petani masih menggunakan cara tradisional dalam mengidentifikasi hama dan penyakit. Dengan menggunakan sistem pakar diharapkan petani dapat melakukan diagnosis hama dan penyakit kopi secara akurat. Tujuan utama dari penelitian ini adalah membangun sistem pakar berbasis web untuk mendiagnosis hama dan penyakit tanaman kopi. Untuk mengidentifikasi hama dan penyakit tanaman kopi, teknik Breadth First Search digunakan. Data terdiri dari 5 hama, 5 penyakit, dan 28 gejala dari hama dan penyakit pada tanaman kopi. Certainty Factor digunakan untuk menentukan bobot setiap gejala dan nilainya ditentukan oleh pakar dan pengguna. Selanjutnya Certainty Factor secara iteratif dihitung oleh sistem untuk mengukur persentase hasil diagnosis. Untuk mengevaluasi sistem ini, 30 pengguna dipilih dan dikelompokkan menjadi 3 kelompok (pakar kopi, petani dan mahasiswa Fakultas Pertanian, mahasiswa jurusan Ilmu Komputer). Pengguna diminta untuk menilai sistem dengan mengisi kuesioner. Pengguna menyimpulkan bahwa sistem pakar berjalan dengan baik dengan persentase masing-masing $75.56 \%, 73,78 \%$ dan $83.39 \%$.
\end{abstract}

Kata Kunci: Arsip, Waktu, Web

\section{Pendahuluan}

Kearsipan merupakan suatu rangkaian kerja yang teratur, mulai dari proses penciptaan, penerimaan, pengumpulan, pengaturan, pengendalian, pemeliharaan dan perawatan serta penyimpanan suatu dokumen menurut sistem tertentu sehingga saat diperlukan arsip tersebut dapat ditemukan dengan cepat dan tepat. Saat dibutuhkan, suatu arsip dapat ditemukan dengan cepat

dan tepat. Bila arsip-arsip tersebut tidak bernilai guna lagi, maka harus dimusnahkan.

Kearsipan memegang peranan penting dalam efektifitas kegiatan dalam sebuah perusahaan atau suatu organisasi. Yakni sebagai sumber informasi dan sebagai sumber referensi bagi suatu perusahaan organisasi. Mengingat arti pentingnya kearsipan atau Filling system, pemerintah Indonesia bahkan menaruh perhatian yang cukup besar 
terhadap kearsipan. Hal ini dapat terlihat dengan adanya peraturan dan perundangan yang mengatur tentang kearsipan Nasional.[1]

Namun Sistem penyimpanan arsip dan dokumen pada perusahaan-perusahaan besar saat ini masih banyak yang manual hingga sering sekali arsip berantakan dan bahkan sulit ditemukan pada saat dibutuhkan sehingga pekerjaan menjadi kurang efektif. Dan tidak sedikit pula karyawan yang mengambil arsip dan dokumen secara sembarangan. Pada perusahaan besar sudah pasti menyimpan banyak sekali arsip penting yang sewaktu-waktu akan diperlukan atau dipinjam. Masalahnya adalah karena banyak nya arsip dan penyimpanan arsip tidak teratur akan memakan waktu sehingga kurang efisien di pt dan peminjaman arsip tanpa ada nota atau bukti peminjaman berisiko arsip hilang ataupun rusak. Dapat disimpulkan bahwa solusi untuk mengatasi masalah diatas adalah dengan dibuatnya suatu aplikasi untuk mengelola dokumen dan arsip pada PT.Pos Indonesia agar Sistem kearsipan dapat berjalan lebih teratur.

\section{Metodologi}

\section{A. Metode Pengumpulan Data}

Teknik pengumpulan data yang dilakukan dalam penelitian ini adalah

\section{Observasi}

Dalam penelitian ini, peneliti melakukan observasi pada Subbag Arsip Bagian Administrasi Biro Umum pada suatu perusahaan di jakarta untuk mendapatkan data tentang perangkat sistem kearsipan, proses kearsipan secara elektronik, dan proses kearsipan secara konvensional.

\section{Studi Pustaka}

Selain dengan melakukan observasi,peneliti juga melakukan studi pustaka dengan mengumpulkan data data yang dibutuhkan untuk referensi penulisan Penelitian dengan membaca buku, jurnal dan karya ilmiah lainnya, yang berhubungan dengan system kearsipan dan dokumen didapatkan melalui berbagai media baik media cetak maupun internet.

\section{Kuesioner}

Kuesioner yang dilakukan melalui platform Google Form yang ditujukan kepada karyawan-karyawan yang diperusahaannya terdapat arsip-arsip penting dan mengetahui system kearsipan yang diterapkan oleh perusahaan tempat mereka bekerja. Ini bertujuan untuk perbandingan dengan Sistem kearsipan yang telah dirancang oleh peneliti, serta meminta pendapat tentang rencana pembuatan aplikasi pengelolaan dokumen dan arsip berbasis web.

\section{B. Metode Pengembangan}

Salah satu faktor yang harus diperhatikan ketika ingin membangun sebuah aplikasi adalah pada tahap pengembangan. Peneliti menggunakan metode waterfall, metode ini menggambarkan pendekatan yang sistematis dan berurutan pada pengembangan perangkat lunak, yang memiliki tahapan-tahapan seperti berikut ini:

\section{a. Tahapan Desain}

Pada tahapan desain ini peneliti menggunakan software Adobe XD untuk membuat tampilan antar muka atau Interface sistem. Tahapan desain ini mengacu pada hasil analisis yang telah dilakukan. Dalam tahapan ini, penulis melakukan desain tampilan yang diharapkan mudah untuk digunakan oleh pengguna manapun. Mulai dari tampilan awal, tampilan tombol-tombol, hingga tampilan input dan output yang akan ditampilkan.

\section{b. Tahapan Pengkodean / Coding}

Tahapan pengkodean merupakan tahapan yang berkaitan dengan tahapan desain, tahapan ini menggunakan Software Sublime Text sebagai script editor, serta penyimpanan database yang menggunakan MySQL.

\section{c. Tahapan Pengujian / Testing}

Setelah tahapan pengkodean selesai maka akan masuk pada tahapan pengujian/testing. Sebelum digunakan oleh User System akan diuji terlebih dahulu apakah Sistem berjalan sesuai dengan yang diharapkan atau ada kendala maupun masalah yang terjadi pada Sistem. Serta melihat apakah fungsi dari system berjalan dengan baik dan lancar.

\section{d. Tahapan Maintenance}

Pada tahapan ini Perangkat lunak yang sudah selesa dibuat kemudian dijalankan serta mengacu pada perbaikan dan pemeliharaan.termasuk dalam memperbaiki kesalahan yang tidak di temukan pada tahapan sebelumnya. Juga melakukan pengembangan pada fitur-ftur yang ada dalam Sistem. Pada tahapan ini juga dilakukan apabila ada kritikan dan saran dari pengguna Sistem.

\section{Hasil dan Pembahasan}

Sistem kearsipan pada perusahaan-perusahaan besar yang ada pada saat ini kebanyakan masih menggunakan metode manual hingga sering sekali arsip berantakan dan bahkan sulit ditemukan pada saat dibutuhkan sehingga pekerjaan menjadi kurang efektif. dan tidak sedikit pula karyawan yang mengambil arsip dan dokumen secara sembarangan. Maka dibuat Aplikasi pengelolaan arsip sebagai media untuk mengatur system kearsipan agar lebih teratur.

\section{A. Use Case Diagram}

Penjelasan tentang Use Case Diagram yang diusulkan pada pembuatan aplikasi ini adalah sebagai berikut :

Pada gambar 1 terdapat 2 aktor yaitu Admin dan User. Admin dapat melakukan Login kedalam aplikasi dan dapat mendaftarkan User agar User dapat mengakses aplikasi. Selain itu admin juga dapat mengelolah data 
divisi, data karyawan dan data arsip. Setelah didaftarkan oleh Admin, User dapat login aplikasi dan dan melakukan transaksi arsip. User dapat melakukan penyimpanan arsip, Peminjaman Arsip, dan Pencarian arsip. Setelah User melakukan transaksi arsip maka Admin akan mengkonfirmasi transaksi arsip. Admin dapat mengkonfirmasi Request penyimpanan arsip, request peminjaman arsip dan pengembalian arsip. Admin juga dapat mengupload file-file non kearsipan ke aplikasi yang dapat didownload oleh User/Karyawan. Setelah transaksi dan konfirmasi kearsipan sudah selesai makan admin dapat membuat laporan kearsipan untuk diberikan kepada atasan. Laporan kearsipan terdiri dari laporan penyimpanan, laporan peminjaman dan laporan pengembalian.

\section{B. Activity Diagram}

Pada gambar 2 activity diagram ini lebih memfokuskan pada proses ketika User melakukan transaksi arsip yaitu penyimpanan arsip,peminjaman arsip dan pengembalian arsip.

\section{Class Diagram}

Pada gambar 3 merupakan rancangan class diagram yang akan digunakan dalam membangun aplikasi Pengelolaan Dokumen dan Arsip berbasis web ini.

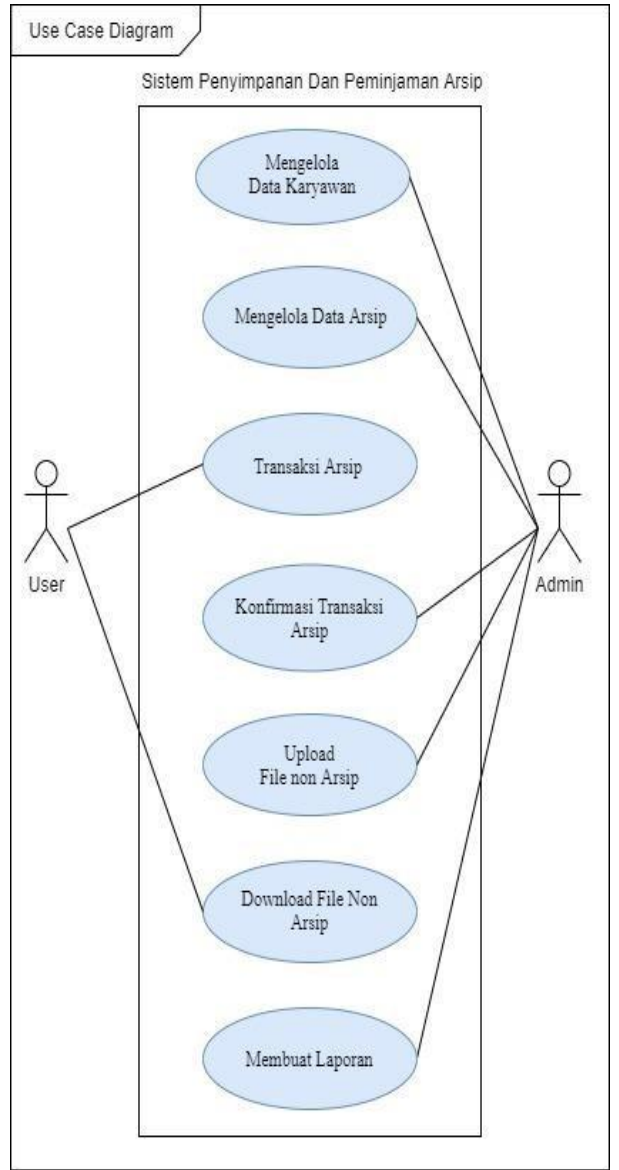

Gambar 1. Use Case Diagram 


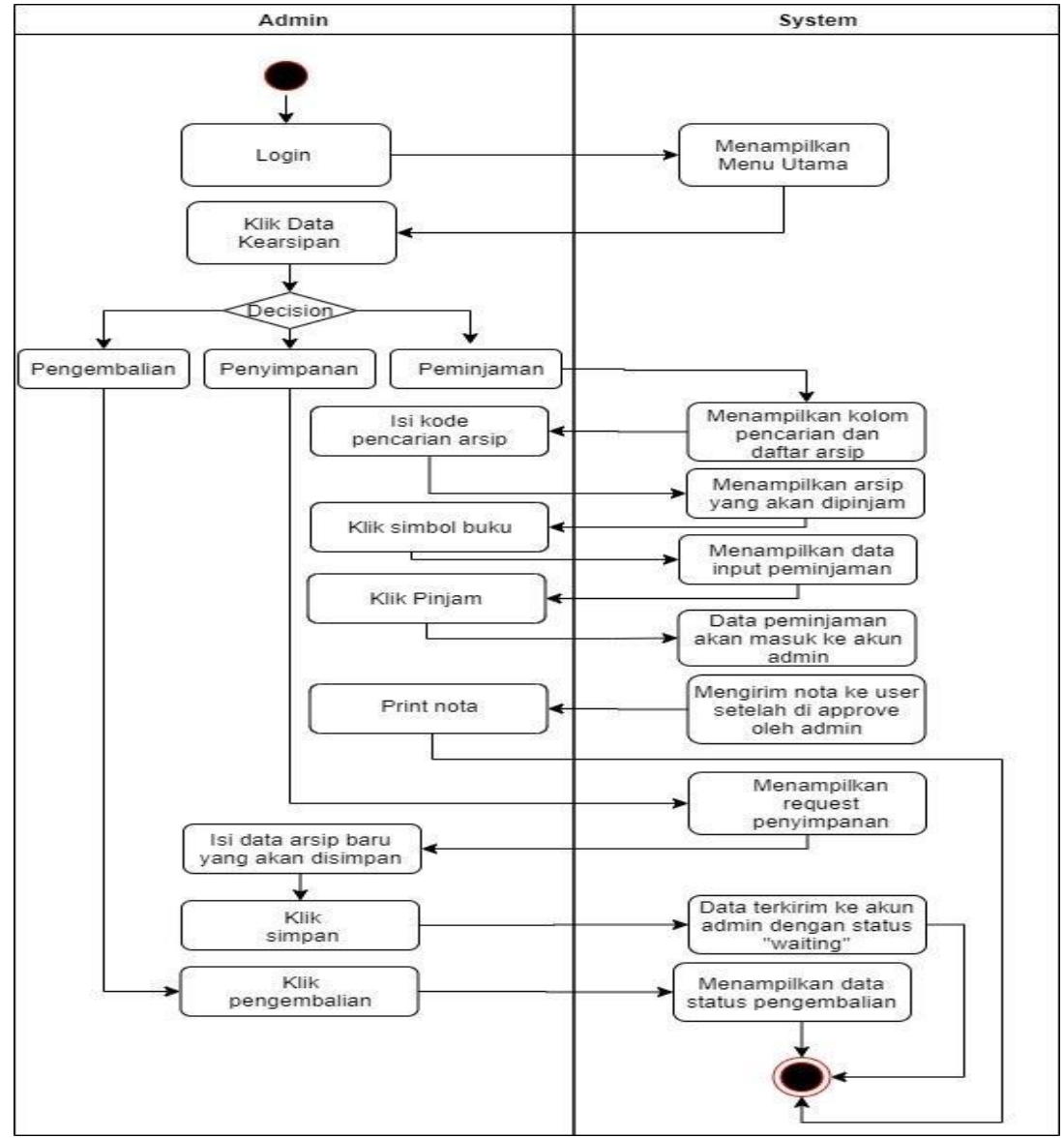

Gambar 2. Activity Diagram

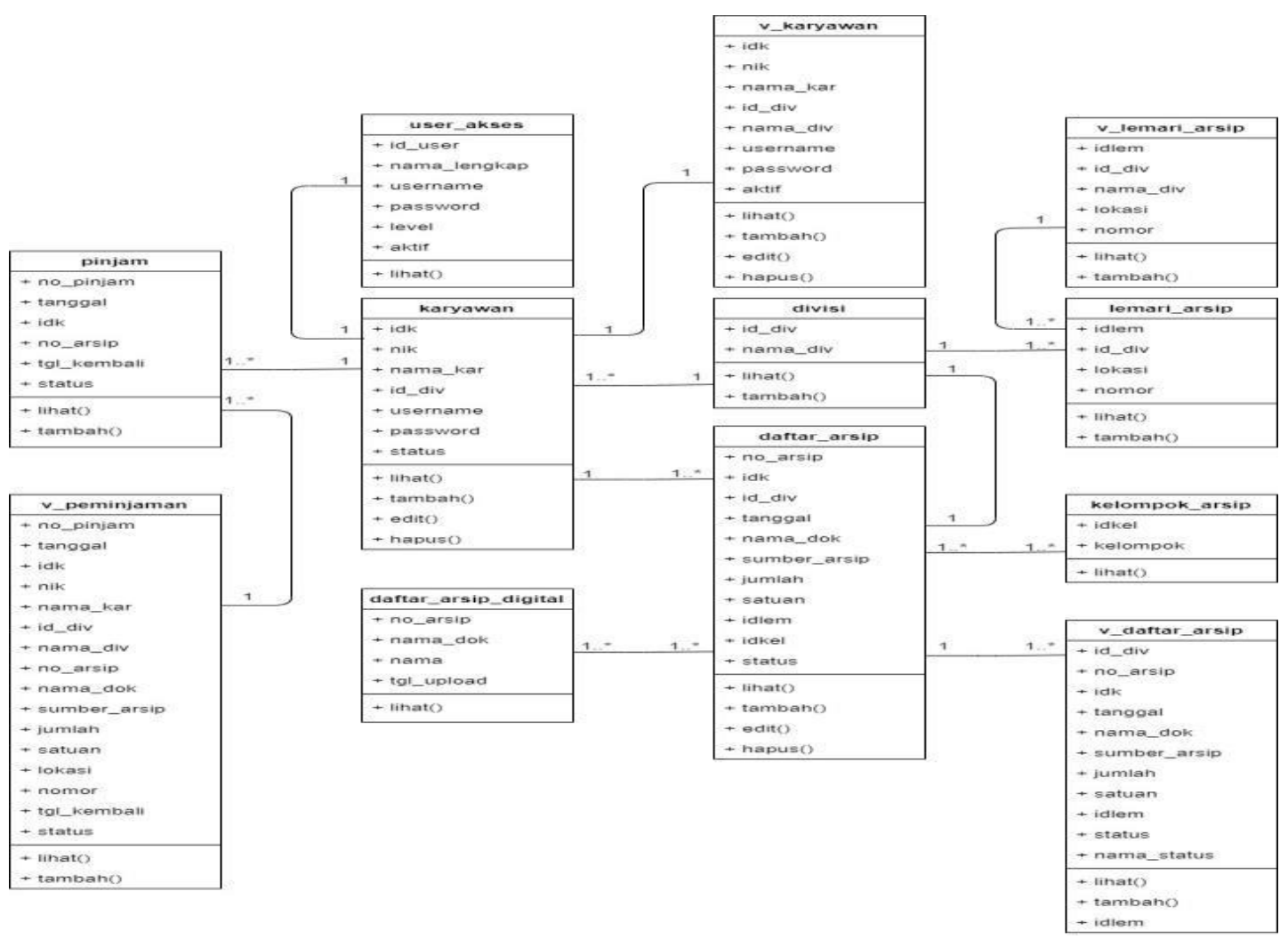

Gambar 3. Class Diagram 


\section{Hasil}

Hasil dari penelitian ini adalah akan dihasilkannya sebuah aplikasi pengelolaan dokumen dan arsip berbasis web dengan fitur utama yaitu transaksi arsip. Pada Gambar 4 merupakan tampilan login(admin).tampilan yang sama juga terdapat pada aplikasi User untuk dapat mengakses aplikasi.
Pada Gambar 5 merupakan halaman form register. Pelanggan melakukan isi data registrasi agar mendapatkan akun dan bisa login kedalam aplikasi

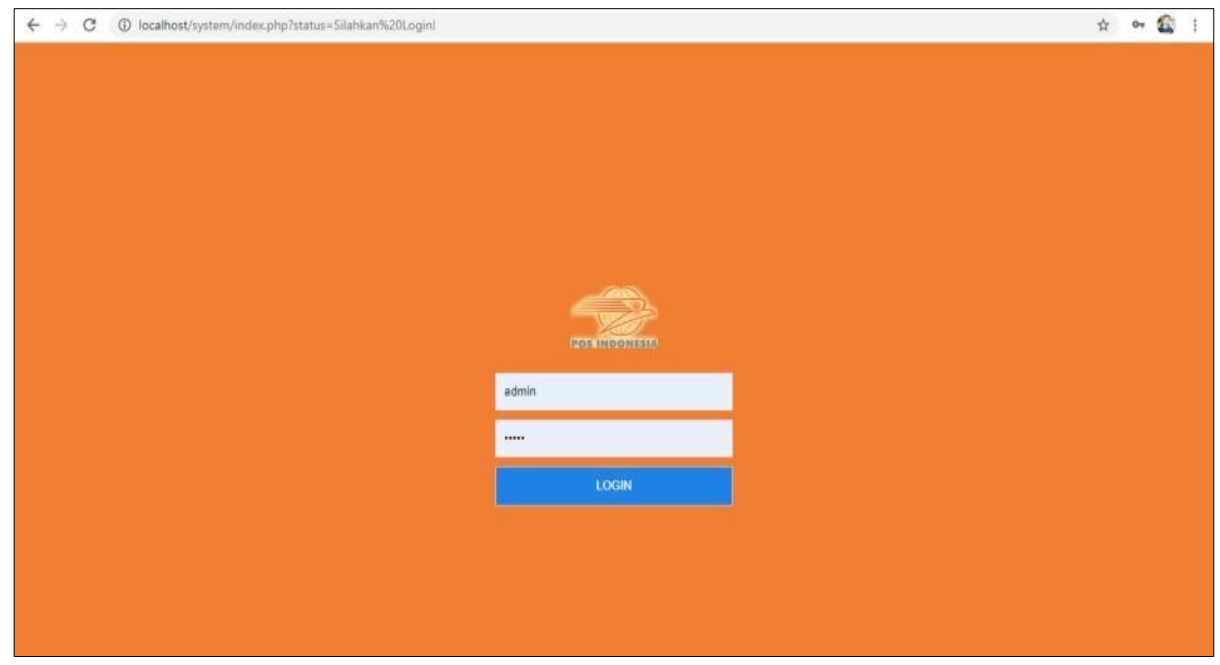

Gambar 4. Halaman Login

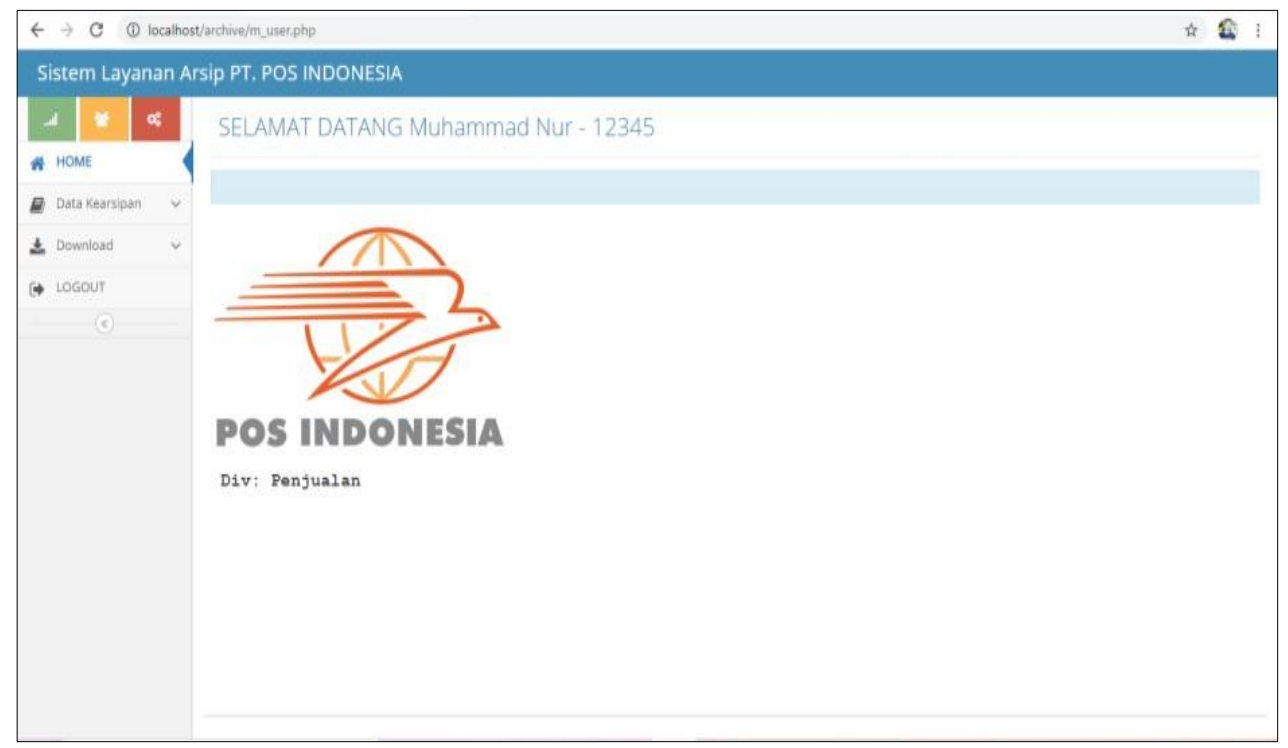

Gambar 5. Halaman Utama 
Pada Gambar 6 merupakan halaman Penyimpanan Arsip dan dokumen. User memasukkan data arsip untuk di kirim ke akun admin.
Pada Gambar 7 merupakan halaman Pencarisan dan Peminjaman Peminjaman Arsip. Pelanggan User/Karyawan mencari arsip yang akan dipinjam dan melakukan transaksi peminjaman arsip.

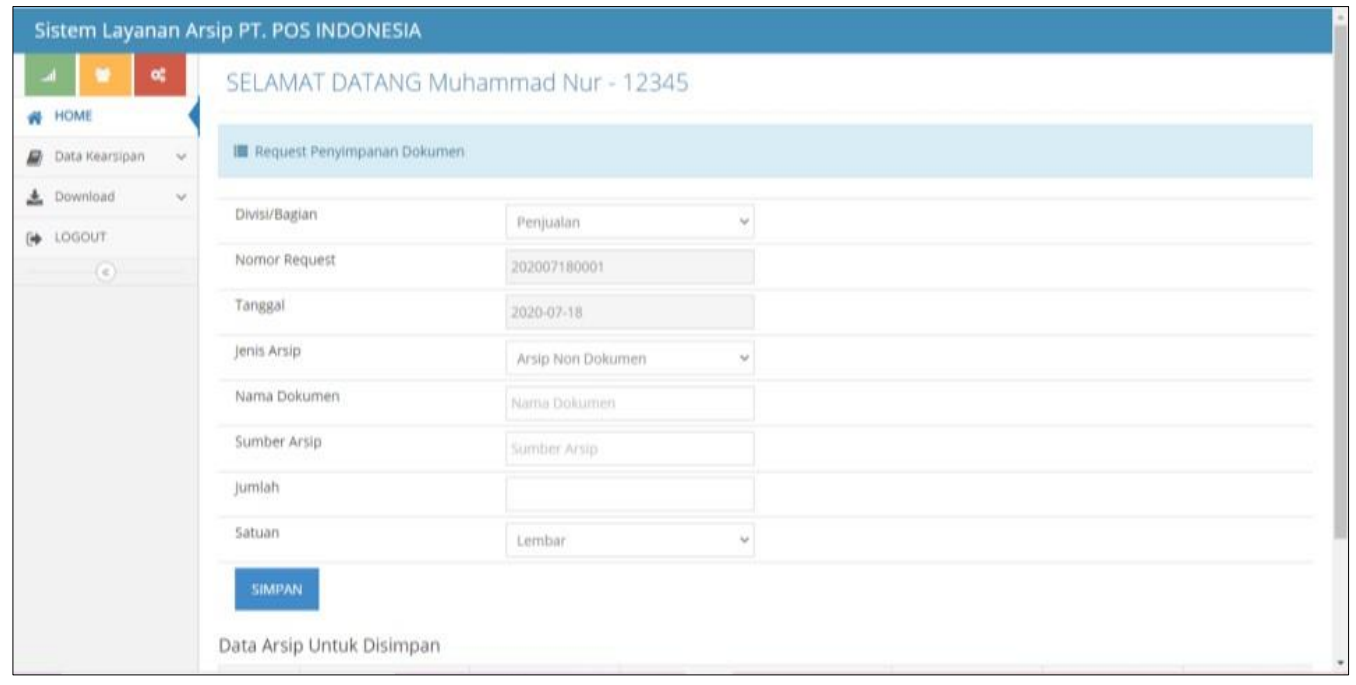

Gambar 6. Tampilan Penyimpanan Arsip

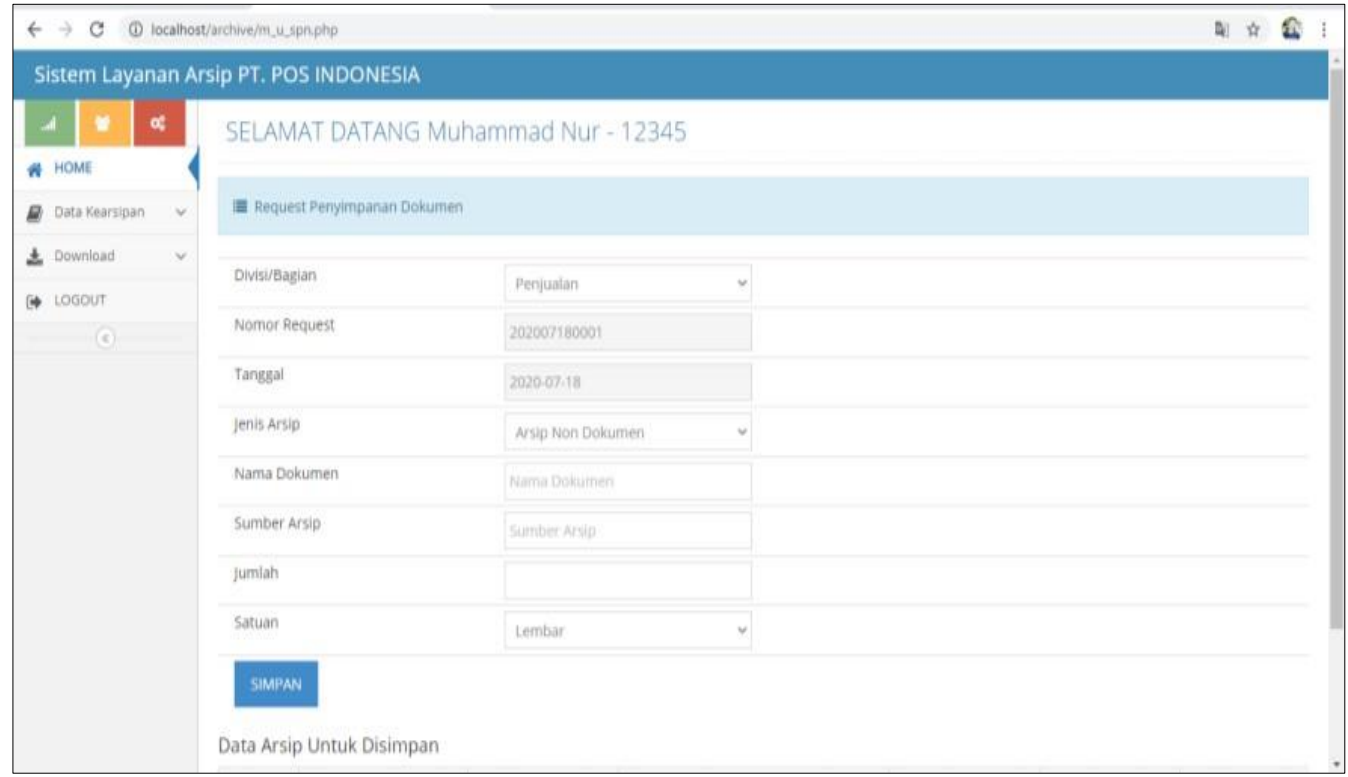

Gambar 7. Tampilan Peminjaman Arsip

\section{Kesimpulan}

Dengan dibuatnya aplikasi pengelolaan dokumen dan arsip berbasis web ini dapat membantu system kearsipan pada prusahaa-perusahaan besar atau organisasi yang memiliki banyak arsip agar system kearsipannya berjalan lebih teratur dan terkonsep, Untuk mengurangi risiko pencarian arsip yang memakan waktu, Kerusakan arsip, Kehilangan arsip serta penyimpanan arsip yang berantakan dan tidak tersimpan pada tempatnya. Aplikasi ini diharapkan dapat membuat jalannya proses pekerjaan menjadi lebih efisien.

\section{Daftar Pustaka}

[1] Rinandi Awan Sagita dan Hari Sugiarto, "Penerapan Metode Waterfall Pada Sistem 
Informasi Penjualan Furniture Berbasis Web”, Jurnal Networking, vol.5 p.4, Oktober 2016.

[2] Dian Novianto,"Implementasi sitem informasi pegawai (simpeg) berbasis web menggunakan frame work dan bootstrap", Atma Luhur ,jurnal ilmiah informatika, vol.7 p.1, 2016

[3] M. Destiningrum and Q. J. Adrian, "Sistem Informasi Penjadwalan Dokter Berbasis Web dengan Menggunakan Framework Codeigniter (Studi Kasus: Rumah Sakit Yukum Medical Centre)," Jurnal Teknoinfo, vol. 11, p. 32, 2017.

[4] Recki ari Wijaya,Bambang Budi Wiyono,Ibrahim Bafadal, "Pengelolaan kearsipan". Jurnal administrasi dan manajemen pendidikan, Vol 1, P.2, Oktober 2018.
[5] Fauzan Maskyur,Ibnu Makruf Pandu atmaja."Sistem administrasi pengelolaan arsip surat masuk dan surat keluar berbasis web". Jurnal jaringan dan keamanan. Vol. 4, P.3, 2015.

[6] Sri Lestanti, Ardina Desi Susana "Sistem pengarsipan dokumen guru dan pegawai menggunakan metode mixture modelling berbasis web" . Jurnal ilmiah tehnik informatika Vol. 10, P.2, November 2016.

[7] Heri Abi Burachman Hakim "OMEKA-Aplikasi pengelola arsip digital dakam berbagai format". Jurnal pengembangan kearsipan, Vol. 9, P.1, 2016. 